\title{
Management of Traumatic Spinal Fracture in Patient with Coronavirus Disease 2019
}

\author{
Beuy Joob $^{1}$, Viroj Wiwanitkit ${ }^{2}$ \\ ${ }^{1}$ Sanitation 1 Medical Academic Center Bangkok Branch, Bangkok, Thailand \\ ${ }^{2}$ Dr. D. Y. Patil University, Pune, India
}

Dear Editor,

We found that the article on "Management of traumatic spinal fracture in the coronavirus disease 2019 situation" is very interesting. Sornsa-Ard et al. [1] recommended protocols from Thailand for management of the patients. Thailand is the second country that coronavirus disease 2019 (COVID-19) exists and there is already at least one case of COVID-19 in the patient with spine fracture according to local Thai Centers for Disease Control and Prevention report [2]. In that case, the patient is a foreigner with history of road accident and there is no symptom of fever or respiratory disease at initial presentation. Regarding the algorithm, the recommended is based on the assumption that there is already diagnosed spine fracture. Nevertheless, the patient might firstly present with only a history of traumatic injury. An important forgotten issue is the self-prevention of surgeon. It is possible that the COVID-19 might be asymptomatic during the time of diagnosis of spine fracture. The algorithm can result in missed diagnosis. We should recommend that the universal precautions should be used in surgical management of any patients during COVID-19 outbreak crisis.

\section{Conflict of Interest}

No potential conflict of interest relevant to this article was reported.

\section{References}

1. Sornsa-Ard T, Niramitsantiphong A, Liawrungrueang W. Management of traumatic spinal fracture in the coronavirus disease 2019 situation. Asian Spine J 2020 Apr 24 [Epub]. https://doi.org/10.31616/ asj.2019.0183.

2. Yasri S, Wiwanitkit V. Editorial: Wuhan coronavirus outbreak and imported case. Adv Trop Med Pub Health Int 2020;10:1-2.

Received Apr 27, 2020; Accepted Apr 27, 2020

Corresponding author: Beuy Joob

Sanitation 1 Medical Academic Center Bangkok Branch, Bangkok Thailand

E-mail: beuyjoob@hotmail.com 